\title{
A Prospective Study to Evaluate the Demographic Profile and Psychiatric Morbidity in Attempted Suicide Patients Admitted in a Tertiary Care Teaching Hospital
}

\author{
Dishanter Goel \\ Associate Professor, Department of Psychiatry, \\ Teerthanker Mahaveer Medical College \& Research Centre, TMU, Moradabad., UP, India.
}

\begin{abstract}
Background: The number of suicides in India during the last decade has recorded an increase of $25.0 \%$. Suicide attempt rates are found to be higher than rates for completed suicides. This study is aimed to evaluate the sociodemographic profile and psychiatric morbidity in attempted suicide patients.

Material and Methods: 225 consecutive cases of attempted suicide were recruited for the study in the Psychiatry department of Teerthanker Mahaveer Medical College \& Research Centre, Moradabad. Structured proforma containing sociodemographic variables and suicide attempt data was administered. Mini International Neuropsychiatric Interview (M.I.N.I. Plus) was applied to assess the psychiatric disorder and the diagnosis was confirmed using ICD 10.

Results: Majority of the suicide attempters were $<30$ years of age $(64.67 \%)$, men $(58.67 \%)$, education below or up to $7^{\text {th }}$ std. $(67.67 \%)$, married $(5.337 \%)$, low socioeconomic status $(62.67 \%)$ and employed (60.89\%), used oral agents (95.56\%) and made an impulsive attempt (72.44\%). Domestic quarrel $(48 \%)$ and relationship issues $(23 \%)$ were the major reasons for attempt. $59.11 \%$ suffered from a psychiatric disorder and
\end{abstract}

\section{INTRODUCTION}

Suicide is the tragic loss of human life, which is untimely and devastating. Suicidal behaviour is all the more perplexing because it is a conscious volitional act. It is a fatal act due to a complex interaction of social, environmental, biological and cultural factors operating on an individual's life. The scourge of suicidal behaviour touches many lives and knows few boundaries. WHO estimated that 877000 deaths were due to suicide in the year 20021. More than one lakh persons in India lost their lives by committing suicide during the year 2008, the all India rate of suicides being 10.8. However, Sikkim reported the highest rate of suicide (48.2) followed by Puducherry (46.9) and suicide rate in Andhra Pradesh was 17.4 in $2008^{2}$. Suicide attempt rates are found to be $10-40$ times higher than rates for completed suicides ${ }^{3}$.

Consistent cross-national risk factors included being female, younger, less educated, unmarried and having a mental disorder ${ }^{4}$. The strongest diagnostic risk factors were found to be mood disorders in high-income countries but impulse control disorders in major depressive episode (27.56\%) was found to be most common diagnosed disorders.

Conclusion: The presence of psychiatric morbidity was observed to confer a considerable risk of suicide.

Key Words: Attempted Suicide, Psychiatric Morbidity.

${ }^{*}$ Correspondence to:

Dr Dishanter Goel

Associate Professor, Department of Psychiatry,

Teerthanker Mahaveer Medical College \& Research Centre, TMU, Moradabad., UP, India.

Article History:

Received: 16-07-2016, Revised: 04-08-2016, Accepted: 24-08-2016

\begin{tabular}{|l|c|}
\hline \multicolumn{2}{|c|}{ Access this article online } \\
\hline Website: & Quick Response code \\
www.ijmrp.com & \\
DOl: &
\end{tabular}

low- and middle-income countries ${ }^{4}$. One or more diagnosis on axis 1 was made for $93 \%$ of victims and the most prevalent disorders were depressive disorders and alcohol dependence 5 .

Human beings are unique, as are their reasons for suicide. National Crime Records Bureau statistics state that social and economic causes have led most of the males to commit suicide whereas emotional and personal causes have mainly driven females to end their lives ${ }^{2}$. Methods used for suicidal attempts are mostly "non-violent" and in the WHO Multicentric study; 64 per cent of males and 80 percent of females used self-poisoning ${ }^{6}$. There is difference in the methods used between countries and this may be related to the differences in the accessibility of certain methods. More than $50 \%$ of the suicide attempters made more than one attempt, and nearly $20 \%$ of the second attempts were made within 12 months after the first attempt ${ }^{3}$. Socio demographic risk factors associated with repetition are belonging to the age group of 25 to 49 years, being divorced, unemployed, and coming 
from low social class ${ }^{6}$. In this above back ground the present study has been undertaken with the aim to assess the role of socio demographic correlates and psychiatric disorders in attempted suicide in a general hospital in rural area.

\section{MATERIAL AND METHODS}

The present study was conducted in the Department of Psychiatry, Teerthanker Mahaveer Medical College \& Research Centre, Moradabad. Two hundred and twenty-five consecutive patients, referred to the Department of Psychiatry with a history of attempted suicide and fulfilling the following description "A person who had made deliberate act of self-harm consciously aimed at self-destruction, irrespective of his or her intention to die, with nonfatal outcome"7 were recruited for the study. Patients with mental retardation and those who refused to give consent were excluded from the study. All the suicide attempters after receiving immediate medical management from the emergency room were shifted to the General medicine department. The patients are then referred to the psychiatry department for evaluation as soon as they were fit for interview considering the medico-legal issues. These subjects were assured of confidentiality of information after explaining the purpose of the study and were recruited for the study after taking written informed consent. Socio- demographic data and suicide attempt data were taken from the patients. M.I.N.I Plus 5.0.0 (Mini International Neuropsychiatric Interview) was administered to assess psychiatric illness and the diagnosis was confirmed in accordance to ICD 10. A supportive psychotherapeutic relationship was maintained with all the subjects till they were discharged.

A structured interview was designed in the department of psychiatry keeping in view all the requirements, which are necessary for the study. The socio-demographic details included are age, sex, marital status, education, occupation, and socio economic status. The Suicide attempt data included nature of attempt, prior thoughts of attempt, history of previous suicidal attempts, reasons for attempt and mode of attempt. Data was entered and analysed using Microsoft Excel and the results were expressed as proportions and percentages.

\section{RESULTS}

In our study $64.67 \%$ of the sample was below 30 years of age. Male predominance $(58.67 \%)$ was observed. Most of the study subjects were married $(57.33 \%)$, employed $(60.89 \%)$, educated upto $7^{\text {th }}$ std. $(67.67 \%)$ and belonged to low socioeconomic status $(62.67 \%)$ as shown in Table 1. Suicide attempt data is shown in Table 2. Majority of the subjects $(72.44 \%)$ made an impulsive suicide attempt and $77.78 \%$ of the sample did not have prior suicidal thoughts. Only $9.33 \%$ presented with a history of previous suicidal attempt. The most frequent method adopted for attempting suicide was the consumption of oral agents (95.56\%). Among the oral agents insecticide was consumed by $47.56 \%$ followed by rat poison (17.78\%). Domestic quarrels (48\%) were found to be the most common reason for the suicidal attempt followed by relationship issues (23\%) and financial problems (18\%). At least one psychiatric disorder was observed in $59.11 \%$ of the suicide attempters as shown in Table 3. Major depressive episode was diagnosed in $27.56 \%$ followed by alcohol dependence in $12 \%$, adjustment disorder in $8 \%$ and dysthymia in $4.89 \%$.
Table 1: Sociodemographic Characteristics

\begin{tabular}{lc}
\hline Variables & No. of subjects $(\%)$ (n=150) \\
\hline AGE & $55(25.44 \%)$ \\
$<20$ & $90(40 \%)$ \\
$21-30$ & $49(21 \%)$ \\
$31-40$ & $21(9 \%)$ \\
$41-50$ & $10(5 \%)$ \\
$>51$ & \\
GENDER & $132(58.67 \%)$ \\
Male & $93(41.33 \%)$ \\
Female & \\
EDUCATION & $91(40.44 \%)$ \\
Illiterate & $60(26.67 \%)$ \\
1st - 7th std. & $30(13.33 \%)$ \\
8th - 10th std. & $23(10.22 \%)$ \\
Intermediate & $21(9.33 \%)$ \\
Degree & \\
MARITAL STATUS & $70(31.11 \%)$ \\
Unmarried & $129(57.33 \%)$ \\
Married & $16(7.11 \%)$ \\
Single/divorced & $10(4.44 \%)$ \\
Widowed & \\
EMPLOYMENT STATUS & $137(60.89 \%)$ \\
Employed & $28(12.44 \%)$ \\
Unemployed & $36(16.00 \%)$ \\
Housewife & $24(10.67 \%)$ \\
Student & $141(62.67 \%)$ \\
SOCIOECONOMIC STATUS & $75(33.33 \%)$ \\
Lower & $9(4.00 \%)$ \\
Middle & \\
Higher & \\
\hline & \\
\hline &
\end{tabular}

Table 2: Suicide Attempt Data

\begin{tabular}{lc}
\hline Variables & No. Of subjects (\%) (n=150) \\
\hline NATURE OF ATTEMPT & $163(72.44 \%)$ \\
Impulsive & $54(24.00 \%)$ \\
Planned & $8(3.56 \%)$ \\
Unable to decide & \\
PRIOR SUICIDAL THOUGHTS & $50(22.22 \%)$ \\
Present & $175(77.78 \%)$ \\
Absent & \\
HISTORY OF PREVIOUS ATTEMPTS & $21(9.33 \%)$ \\
Yes & $204(90.67 \%)$ \\
No & \\
MODE OF ATTEMPT & $107(47.56 \%)$ \\
Insecticide poisoning & $12(5.33 \%)$ \\
Herbicide poisoning & $40(17.78 \%)$ \\
Rat poison & $6(4.00 \%)$ \\
Fungicide & $15(6.67 \%)$ \\
Drug overdose & $6(2.67 \%)$ \\
Kerosene & $5(2.22 \%)$ \\
Gammaxene & $4(1.78 \%)$ \\
Bleaching powder & $6(22.67 \%)$ \\
Disinfectant liquids & $11(4.89 \%)$ \\
Unknown poison & $10(4.44 \%)$ \\
Hanging & $27(18 \%)$ \\
REASONS FOR ATTEMPT & $34(23 \%)$ \\
Financial problems & $72(48 \%)$ \\
Relationship issues & $6(4 \%)$ \\
Domestic quarrel & $11(7 \%)$ \\
Medical illness & \\
Failure in examination & \\
\hline & \\
&
\end{tabular}


Table 3: Psychiatric Disorder

\begin{tabular}{lc}
\hline Psychiatric Disorder & No. of subjects $(\%)(\mathbf{n = 1 5 0})$ \\
\hline Major depressive episode & $62(27.56 \%)$ \\
Dysthymia & $11(4.89 \%)$ \\
Panic disorder & $3(1.33 \%)$ \\
Alcohol dependence & $27(12 \%)$ \\
Adjustment disorder & $18(8 \%)$ \\
Schizophrenia & $3(1.33 \%)$ \\
Delusional disorder & $3(1.33 \%)$ \\
Bipolar disorder & $6(2.67 \%)$ \\
No psychiatric diagnosis & $92(40.89 \%)$ \\
\hline
\end{tabular}

\section{DISCUSSION}

In the present study, we obtained the data on sociodemographic and suicide attempt profile, and psychiatric morbidity of the subjects with history of attempted suicide presenting to a general hospital situated in rural area. The study group consisted of one hundred and fifty subjects. The data obtained in our sample was consistent with few earlier studies. ${ }^{9,10}$

\section{Age}

In our study majority of the suicide attempters were below 30 years of age $(64.67 \%)$. Similar observations were made in most of the Indian studies. ${ }^{9-11}$ Individuals below 30 years of age were found to be more vulnerable for attempting suicide. ${ }^{12,13}$

\section{Gender}

Male predominance was observed in our study. Males were found be $58.67 \%$ and females $41.33 \%$, which is in accordance to the findings reported in earlier studies from India. ${ }^{10-13}$ Contrary to the above female gender preponderance was observed in few studies. ${ }^{9,14}$ However no such gender difference was observed by Nilamadhab Kar ${ }^{15}$ and Partha Praatim Das et al. ${ }^{16}$

\section{Education status}

Most $(67.67 \%)$ of the subjects in our study were educated below or up to $7^{\text {th }}$ standard, similar results were observed in other studies. ${ }^{9,12,15}$ Educational disadvantage is a contributory risk factor domain. ${ }^{17}$ However, Partha Praatim Das et al. ${ }^{16}$ reported that majority of attempters were educated beyond matriculation (75\%).

\section{Employment}

In our study majority $(60.89 \%)$ of the subjects were employed, working in the agricultural sector. Similar results were reported by R.Chandrasekharan et al. ${ }^{9}$ As opposed to this, unemployment was found to be significantly associated with suicide in previous literature from India and the West.7,14,15,18

\section{Marital status}

Our data showed that most $(57.33 \%)$ of the suicide attempters were married which confirms the trend observed by earlier studies. ${ }^{7,16}$ However study from Denmark reported cohabiting or single marital status was a significant risk factor for suicide. ${ }^{18}$ Being separated or divorced was noted to be significantly associated with a suicidal act in another study. ${ }^{14}$

\section{Socioeconomic status}

The observation made in our study that maximum number of suicide attempters belonged to low socioeconomic status $(60.89 \%)$ is in accordance with the findings of most Indian studies. ${ }^{12,13,15}$

\section{Mode of attempt}

Oral agents were used for attempting suicide by majority (95.56\%) subjects in our study. Among the oral agents insecticide was consumed by $47.56 \%$ followed by rat poison ( $17.78 \%$ ), herbicide by $5.33 \%$ and fungicide by $4 \%$. Previous studies on attempted suicide reported similar observations that poisoning was the predominantly used method.7,9,10,12,13 In our study, as all the suicide attempters were from rural background, majority were working in agricultural sector. Insecticides, rat poison, herbicide, fungicide and gammaxene were regularly procured and used for the agricultural purposes. There appears to be a relationship between the occupation (agriculture) and method used as pointed out by Takeshi Sato et al. ${ }^{19}$ Easy availability of these compounds within the home or premises rendered them the first preference for attempting suicide. ${ }^{11,20}$ An association is observed between method availability and method specific suicide rates. ${ }^{17,21}$

B.A.J. van Spijke 22 reported that impulsivity plays an important role in self-poisonings, as well as aggression and easy accessibility of pesticides. In our study in majority $(72.44 \%)$ of the subjects it was an impulsive suicide attempt whereas J. John Mann., et al. ${ }^{23}$ reported that $46.7 \%$ were planned attempters. Only $24 \%$ of the our study subjects had prior suicidal thoughts which coincided with the statistical figure (about 23\%) of the study conducted by R. Ponnudurai et al. ${ }^{10}$

Domsetic quarrels (48\%) and relationship issues (23\%) were found to be the major reasons to attempt suicide in our study which confirms the trend of other studies from India. .0,15,16 $^{-1}$ Financial problems (18\%) seemed to notable cause leading to suicide which is similar to the observations made in few earlier studies. 7,15

\section{Psychiatric disorder}

In our study $59.11 \%$ of the suicide attempters suffered from a psychiatric disorder and major depressive episode (27.56\%) and alcohol dependence $(12 \%)$ were found to be most common diagnosed disorders. Similarly results were reported by few investigators. ${ }^{9,24}$ On the contrary, in other studies it was observed that about $90 \%$ were diagnosed with at least one psychiatric disorder. 5,13,25 Co morbidity of two or more psychiatric disorders was also reported. ${ }^{25}$

\section{CONCLUSION}

The current study has several limitations. First, the Sample size is small and sample constitutes of purely rural population, therefore cannot be extrapolated to a large sample and generalised to a general population. Second, this study has shown only $4 \%$ representation from higher socio economic status as the sample is from a general hospital. Third, some psychiatric disorders like personality disorders not found in the M. I. N. I. PLUS (which could have led to suicide attempt) might have been missed. Even with the above limitations this study served the purpose of treating the psychiatric morbidity as well as other causes of attempted suicide in the study population. It is a study of its kind which is done purely on a rural population and standard instruments were used.

Thus, it can be concluded that considerable number of attempters suffered from psychiatric disorder. Early diagnosis of the psychiatric disorders and supportive measures for various stressors would help in prevention of suicidal attempts. Lack of restriction for procurement of oral agents, easy availability and impulsive nature of the attempts may be the reason for the preference to use these agents for attempting suicide. Taken together these findings, our results lead us to the conclusion that the variables enhancing the risk of suicide among the vulnerable 
groups if identified and the predictive items associated with suicidal risks are enlisted, it would effectively help in early detection and prevention of suicide attempts. Thus, many a life could be saved in time.

\section{REFERENCES}

1. The world health report: shaping the future. Geneva: WHO; 2003.

2. National crime records Bureau, Accidental deaths and Suicides in India, Ministry of Home Affairs, Govt. of India, 2008.

3. Schmidtke, A., Bille-Brahe, U., DeLeo, D., Attempted suicide in Europe: rates, trends and sociodemographic characteristics of suicide attempters during the period 1989-1992. Results of the WHO/EURO Multicentre Study on Parasuicide. Acta Psychiatrica Scandinavica, 1996; 93(5):327-338.

4. Matthew K. Nock, Guilherme Borges, Evelyn J. Bromet, Jordi Alonso, Matthias Angermeyer, Annette Beautrais. Cross-national prevalence and risk factors for suicidal ideation, plans and attempts. The British Journal of Psychiatry 2008; 192:98-105.

5. Henriksson MM, Aro HM, Marttunen MJ, Heikkinen ME, Isometsä ET, Kuoppasalmi KI, Lönnqvist JK. Mental disorders \& Co morbidity in Suicide. Am J Psychiatry 1993; 150(6):935-940.

6. A.J.F.M. Kerkhof \& E. Arensman, Attempted suicide and deliberate self-harm: epidemiology and risk factors, 4.15.2, 10391044, vol.1, New Oxford Textbook of Psychiatry, 2000. Oxford University Press, New York.

7. MK Srivastava, RN Sahoo, LH Ghotekar, Srihari Dutta, M. Danabalan, TK Dutta, AK Das. Risk factors associated with Attempted Suicide: A case control study. Indian Journal of Psychiatry 2004; 46(1):33-38.

8. [http://www.nccpsychiatry.info/File/MINI500.pdf] Mini International Neuropsychiatric Interview English Version5.0.0, DSM-IV. 9. R Chandrasekaran, J Gnanaseelan, Ajith Sahai, R. P Swaminathan, Bojir Perme. Psychiatry and personality disorders in survivors following their first suicide attempt. Indian Journal of Psychiatry 2003; 45(2):45-48.

10. R Ponnudurai, J.Jey Akar, M. Saraswathy. Attempted suicide in Madras. Indian Journal of Psychiatry 1986; 28(1): 59-62.

11. Venkoba Rao.A. Attempted Suicide. Indian Journal of Psychiatry 1965; 7(4): 253-264.

12. R.L Narang, B.P. Mishra \& Nitesh Mohan. Attempted suicide in Ludhiana. Indian Journal of Psychiatry 2000; 42 (1): 83-87.

13. Suresh Kumar. P. N. Age \& Gender related analysis of psychosocial factors in attempted suicide- study from a medical intensive care unit. Indian Journal of Psychiatry 1998; 40(4): 338345.

14. Emma Robertson Blackmore, Sarah Munce, Iris Weller, Brandon Zagorski, Stephen A. Stansfeld, Donna E. Stewart, Eric D. Caine and Yeates Conwell. Psychosocial and clinical correlates of suicidal acts: results from a national population survey. The British Journal of Psychiatry 2008; 192: 279-284.

15. Nilamadhab Kar. Profile of risk factors associated with suicide attempts: A Study from Orissa, India. Indian Journal of Psychiatry 2010; 52(1): 48-56.
16. Partha Pratim Das, Sandeep Grover, Ajit Avasthi, Subho Chakrabarti, Savita Malhotra, and Suresh Kumar. Intentional selfharm seen in psychiatric referrals in tertiary care hospital. Indian Journal of Psychiatry 2008; 50(3):187-191

17. Annette L. Beautrais. Methods of youth suicide in New Zealand: trends and implications for prevention. Australian and New Zealand Journal of Psychiatry 2000; 34(3): 413-419.

18. Ping Qin, Esben Agerbo, Preben Bo Mortensen. Suicide Risk in Relation to Socioeconomic, Demographic, Psychiatric, and Familial Factors: A National Register-Based Study of All Suicides in Denmark, 1981-1997. Am J Psychiatry 2003; 160:765-772.

19. Takeshi Sato, Masashi Takeichi, Tomihide Hara. Suicide attempts by agriculture chemicals. Indian Journal of Psychiatry 1993; 35(4): 209-210.

20. Anuradha Bose, Sejbaek, C. S.; Suganthy, P.; Venkata Raghava; Alex, R.;Jayaprakash Muliyil; Konradsen, F. Self-harm and self-poisoning in southern India: choice of poisoning agents and treatment. Tropical Medicine and International Health 2009; 14(7): $761-765$.

21. Peter M. Marzuk, Andrew C. Leon, Kenneth Tardiff, Edward B. Morgan, Marina Stajic, J. John Mann. The Effect of Access to Lethal Methods of Injury on Suicide Rates. Arch Gen Psychiatry 1992; 49 (6):451-458.

22. Van Spijker, B. A. J.; Graafsma, T.; Dullaart, H. I. A.; Kerkhof, A. J. F. M. Impulsive but Fatal Self-Poisoning with Pesticides Among South Asians in Nickerie, Suriname: An Exploratory Autopsy Study. Crisis: The Journal of Crisis Intervention and Suicide Prevention 2009; 30(2): 102-105.

23. J. John Mann, M.D., David A. Brent, M.D., and Victoria Arango. The Neurobiology and Genetics of Suicide and Attempted Suicide: A Focus on the Serotonergic System. Neuropsychopharmacology 2001; 24(5): 467-477.

24. Jie Zhang, Shuiyuan Xiao, Liang Zhou, Mental Disorders and Suicide Among Young Rural Chinese: A Case-Control Psychological Autopsy Study, Am J Psychiatry 2010; 167:773781.

25. Camilla Haw, Keith Hawton, Kelly Houston, Ellen Townsend, Psychiatric and personality disorders in deliberate self-harm patients, The British Journal of Psychiatry 2001;178: 48-54

\section{Source of Support: Nil. Conflict of Interest: None Declared.}

Copyright: (c) the author(s) and publisher. IJMRP is an official publication of Ibn Sina Academy of Medieval Medicine \& Sciences, registered in 2001 under Indian Trusts Act, 1882.

This is an open access article distributed under the terms of the Creative Commons Attribution Non-commercial License, which permits unrestricted non-commercial use, distribution, and reproduction in any medium, provided the original work is properly cited.

Cite this article as: Dishanter Goel. A Prospective Study to Evaluate the Demographic Profile and Psychiatric Morbidity in Attempted Suicide Patients Admitted in a Tertiary Care Teaching Hospital. Int J Med Res Prof. 2016; 2(5):172-75. 